\title{
Introducción al subsector pesquero portuense en el siglo XIX $\left(^{*}\right)(* *)$
}

\section{JAVIER MALDONADO ROSSO}

La ambicomarcalidad de que goza El Puerto de Santa María -integrante de la Bahía de Cádiz y del Marco del jerez- ha jugado históricamente un papel diversificador de sus actividades económicas. Su situación geográfica y las características naturales del término han propiciado, al compás del devenir histórico, el desarrollo de actividades pesqueras, acuícolas y salineras, así como agrícolas y ganaderas. Algunas de éstas, a su vez, han sido, en unos casos, y continúan siéndolo en otros, bases de industrias conserveras y vinícolas. En relación con tales actividades primarias y secundarias, y también al margen de ellas, el comercio marítimo tuvo en diversos periodos una destacadísima importancia en estas tierras. Hasta tal punto fue así que en el último tercio del siglo XVIII constituyó el factor fundamental de un malogrado foco industrial textil en la ciudad, orientado al comercio americano (1).

Ciñéndonos al periodo de nuestro estudio, conviene señalar que en el siglo XIX la localidad presentaba un activo sector secundario, nucleado en torno a la industria vinícola, que actuaba como motor de la economía local (2). En el sector terciario, era el comercio de los

(*) Este trabajo forma parte del proyecto de investigación que, sobre la historia de la pesca en El Puerto de Santa María, llevamos a cabo en el Centro Municipal del Patrimonio Histórico de la indicada ciudad.

(**) Este artículo se presentó como comunicación en las IX Jornadas de Andalucía y América, celebradas en' La Rábida, en 1989. Por razones ajenas al autor y a la entidad organizadora, el texto no pudo llegar a tiempo de ser incluido en el volumen en el que se recogen las actas de tales jornadas, que ha aparecido al público en estos meses veraniegos de 1991. Para la presente edición hemos mantenido en lo esencial el texto original, procediendo tan sólo a matizar ciertos aspectos y a actualizar las notas bibliográficas.

(1) Vid. IGLESIAS, Juan José: Una ciudad mercantil en el siglo XVIII: El Puerto de Santa Maria. Sevilla, 1991, pp. 213-238.

(2) Los inicios de la industria vinícola en el Marco del jerez constituyen el tema de nuestra tesis doctoral, en proceso de elaboración. 
vinos el ramo más importante, en correspondencia con el desarrollo de la citada industria. No obstante, la composición del comercio exterior e interior había sufrido notables cambios y disminuido su dinamismo con respecto al siglo XVIII. La emancipación de las colonias americanas introdujo las últimas modificaciones en un proceso de decadencia que arrancaba desde el siglo anterior. A fines de la centuria, el turismo figuraba para ciertos sectores locales como actividad económica alternativa, de considerable importancia para la población (3). Por su parte, el sector primario se caracterizaba por la extracción de sal, la pesca y la agricultura. Principalmente la viticultura: base de la actividad que constituye la columna vertebral de la economía portuense contemporánea (4).

Esta base económica, apenas esbozada en las líneas que anteceden, está por estudiar; pero nuestro desconocimiento, aunque general, es mayor, si cabe, en lo que respecta a la pesca. Sabemos algo de la importancia de este subsector en periodos anteriores a la contemporaneidad; pero, tal vez porque se parte de la concepción de que la pesca es una actividad típica de economías atrasadas, de economías primarias, en nuestros actuales esquemas historiográficos queda fuera de lugar por lo general. Así, un buen número de estudios historiográficos que abordan el análisis de la economía de localidades en las que existe una actividad pesquera, ésta suele ser obviada. Conviene también reparar, de otra parte, en el hecho de lo escasa que es la historiografía española dedicada al estudio de la pesca (5). Se trata, sin

(3) BORREGO PLA, María del Carmen: "El comercio del vino y El Puerto de Santa María en la crisis del noventa y ocho", en VJornadas de Andalucía y América. Sevilla, 1984, T. I, pp. 453-478.

(4) MALDONADO ROSSO, Javier: La propiedad de la tierra en El Puerto de Santa María a inicios de la Edad Contemporánea, tesina de licenciatura, Universidad de Cádiz, 1986 (inédita); y "El cultivo de la vid en El Puerto de Santa María a principios del siglo XIX", en Actas de las VIII Jornadas de Andalucía y América. Sevilla, 1991, pp. 215-233.

(5) Sin pretensión alguna de exhaustividad, sino tan sólo orientativa para quienes tengan interés en el tema, cabe remitirse a las diferentes investigaciones de Jorge Fernández y Carlos Martínez Shaw sobre la pesca en España y sus colonias americanas, así como en Cataluña durante el Antiguo Régimen. También a las de Eloy Martín Corrales sobre Cataluña y sobre la pesca española en el Norte de Africa. A las de Xan Carmona Badía y García Lombardero sobre las pesquerías gallegas en los siglos XVIII-XIX; y Antonio Meijide Pardo y María Luisa Meijide sobre pesca en Galicia. Para la pesca en Andalucía, aunque sean fundamentalmente estudios geográficos, pueden encontrarse interesantes referencias históricas en los trabajos de Compán Vázquez y de Juan Benito Arranz. José Muñoz Pérez se ocupó de la pesca en Sanlúcar de Barrameda. Sobre la evolución de la pesca española es imprescindible lo elaborado por Luis Urteaga. 
embargo, de una actividad extractiva base de un notorio proceso industrializador y comercializador.

No obstante, a la tónica generalizada de lo que parece ser un escaso interés investigador por este subsector, se une en el caso de $\mathrm{El}$ Puerto al fenómeno de eclipsación de esta actividad producido por la enorme importancia en la economía local de la vitivinicultura (6). Consideramos, empero, la hipótesis de que la pesca ha debido jugar un destacado papel en la economía y la sociedad portuenses contemporáneas. Este trabajo tiene por objeto introducirnos en el conocimiento de este subsector en El Puerto, procurando ofrecer un aspecto general del mismo en el siglo XIX y un análisis más particular de la pesca del bou en la década de los años sesenta de esa misma centuria.

\section{PROBLemAS Metodologicos}

Los datos, escasos por el momento, que poseemos de dos de los principales factores de análisis, nos van a permitir trazar una visión global de la evolución de la pesca en El Puerto durante el siglo XIX. Se trata de la dimensión de la flota pesquera y del volumen de la población activa dedicada a este subsector.

Metodológicamente, las fuentes (7) nos plantean varios problemas de homogeneización de los datos. Estos aparecen, indistintamente, individualizados por localidades o integrados por distritos o provincias marítimas. En este último caso resulta imposible conocer los datos de cada una de las localidades en cuestión; lo que, pese al indudable interés de las fuentes, resta a éstas operatividad para el objeto de nuestro estudio, que se ve así dificultado. De otra parte, en ocasiones, los datos que poseemos de los efectivos humanos y de la dimensión de la flota pesquera corresponden a diferentes fechas, por lo que tampoco resulta posible establecer relaciones entre ambas magnitudes a lo largo del periodo estudiado. En ciertas fuentes bibliográficas utilizadas hay que advertir la existencia de errores. Tal es el caso del opúsculo de Vera y Chilier sobre la pesca en la provincia de Cádiz (8), en el que

(6) No queremos decir con esto que la actividad vitivinícola cuente con suficientes estudios; sino que en la sintesis de la historia de la localidad siempre se hace referencia a la importancia de la misma, al tiempo que se silencia lo relativo a la pesca.

(7) Nos referimos fundamentalmente a la Revista de Matrícula de 1799 (A.M.A.B., Matrículas, G.I., leg. 1883) y a la relación de embarcaciones pesqueras del bou en 1868 (A.M.A.B., Pesca, A.P., leg. 2.137).

(8) VERA Y CHILIER, Francisco Asís de: Memoria sobre la pesca en Cádiz y su provincia. Madrid, 1895. 
haciendo referencia al número de parejas de bous en distintas fechas los datos que se ofrecen corresponden a embarcaciones unitarias; lo que puede ocasionar confusiones y la transmisión de los errores observados. También hay errores apreciables, de similar tipo al señalado, en el anuario de la Comisión Permanente de Pesca de 1868, donde la confusión entre parejas y unidades de embarcaciones del arte del bou origina a su vez equivocaciones en otras magnitudes (9).

A lo señalado vienen a unirse modificaciones administrativas que afectaron a los limites de las provincias marítimas y a la adscripción a ellas de distintas localidades. Aspecto este a considerar por los errores a que puede inducir su desconocimiento, cuando sea preciso operar con algunos de los citados datos integrados. En nuestro caso, El Puerto de Santa María, que a fines del siglo XVIII formaba parte de la provincia marítima de Sanlúcar de Barrameda, pasó a integrarse en la provincia marítima de Cádiz en el primer tercio del siglo XIX.

\section{EFECTIVOS HUMANOS Y MATERIALES}

Hechas estas advertencias, podemos adentrarnos en el tema que nos ocupa. Pero no sin hacer antes una observación taxonómica sobre la pesca. La actividad pesquera, como tantas otras, admite y/o requiere distintas clasificaciones, según los aspectos a que nos refiramos. Puede distinguirse así entre pesca de altura y bajura, y entre pesca marítima y fluvial, etc. Lo que nos interesa, en este caso, son las técnicas pesqueras (10). Al respecto, en el argot pesquero se habla de "artes" de pesca, diferenciándose entre las de "tiro", "arrastre", etc. Cabe, nos parece, una primera división entre "artes de arrastre" y "artes de suspensión". Denominación esta última que proponemos en oposición a aquéllas; pues en tanto que las artes de arrastre barrían los fondos marinos, las que titulamos artes de suspensión se mantenían a distintas alturas, según los casos, bajo la superficie del agua, sin afectar a los fondos marinos; aunque tocándolos en algunos casos. Se trata pues de una denominación que hay que tomar "sensu latu".

La clasificación que de las artes de pesca solía hacerse en los siglos XVIII y XIX no era ésta. No obstante, la proponemos y utiliza-

(9) Anuario de la Comisión Permanente de Pesca, 1868. Madrid, 1869.

(10) Sobre el particular es de imprescindible consulta para los interesados, la monumental obra del que fuera Inspector de Marina, a fines del siglo XVIII, Antonio Sáñez Reguart: Diccionario bistórico de las artes de la pesca nacional, editado en Madrid en cinco volúmenes entre 1791 y 1795. 
mos aquí porque consideramos que se trata de una clasificación básica; apropiada para reflejar, en un primer acercamiento al tema, dos grandes tipos de pesca marítima, en cada una de las cuales hay que distinguir diversas modalidades de pesca: Esta clasificación coadyuva a hacer más comprensible el impacto que supusieron en el siglo XVIII los cambios tecnológicos pesqueros, con el predominio de las modalidades de pesca de artes de arrastre sobre los de pesca de artes de suspensión. Sobre este aspecto habremos de volver más adelante, pero convenía adelantarlo aquí, para que se observen mejor las referencias a la dimensión y características de la flota pesquera portuense; de la que pasamos a ocuparnos ya.

A las puertas del siglo XIX, en octubre de 1799 para ser exactos, eran 49 las embarcaciones pesqueras matriculadas en El Puerto. A finales casi de la centuria, se alcanzaban las 238 unidades (11). Desafortunadamente, la globalidad de los datos de 1799 no nos permite conocer los tipos de embarcaciones, ni la pesca que practicaban, ni el tonelaje de las mismas. Este último dato tampoco lo: disponemos para 1887 , aunque sí conocemos, en cambio, los artes de pesca empleados por la flota en ese año (Apéndice 1). En número de unidades, las embarcaciones pesqueras con artes de suspensión doblaban prácticamente a las de artes de arrastre sin embargo, la importancia de éstas, como tendremos ocasión de señalar más adelante, era más notoria, dado su mayor tonelaje, tripulación y capacidad de captura. Entre éstas destacaban, en casi exclusividad, las parejas de bou. Entre las embarcaciones que empleaban lo que hemos dado en llamar artes de pesca de suspensión sobresalían en número los boniteros, ballestillas, curricanes, nasas, cordeles y terrallas -o tarrayas-. Tanto en términos absolutos como relativos, la flota pesquera matriculada en El Puerto en 1887 estaba ya lejos de los calificados por Jorge Fernández y Carlos Martínez Shaw "contingentes modestos" de 1765, cuando se contabilizaban en esta localidad 23 embarcaciones pesqueras (12). El Puerto no constituía una excepción entre las localidades de la bahía de Cádiz, en lo que a dimensiones de su flota pesquera se refiere: Sanlúcar contabilizaba en esas mismas fechas 11 embarcaciones, y 6 y 2 Cádiz y Rota, respectivamente, según los datos aportados por estos autores; para quienes "la zona

(11) A.M.A.B., Matrículas, G.I., leg. 1883; y VERA Y CHILIER, Francisco Asís de: op. cit., pp. 27 y 38-39.

(12) FERNANDEZ, Jorge y MARTINEZ SHAW, Carlos: "La pesca en la España del siglo XVIII. Una aproximación cuantitativa (1758-1765)", en Revista de Historia Económica, 3, 1984, pp. 183-201. 
comprendida entre Huelva y Ayamonte" constituía entonces el centro de gravedad de la pesca en la Andalucía Atlántica (13).

En lo que se refiere a los efectivos humanos dedicados a la actividad pesquera, su conocimiento plantea ciertas dificultades. A los problemas metodológicos de carácter general señalados líneas atrás, se une en este caso otro específico, cuando se tiene la fortuna de contar con fuentes al respecto. Las revistas de matrícula, dado su carácter militar, recogían -o trataban de hacerlo- a cuantos varones se dedicasen a cualesquiera actividades económicas marítimas. En consecuencia, en las mismas se contabilizan tanto las personas dedicadas directamente a la actividad pesquera y al tráfico naval, conocidas como "gente de mar", como a las empleadas en oficios de "maestranza" (14). Cuando los datos aparecen globalmente recogidos como "matriculados", no nos es posible conocer el número de pescadores. Tampoco cuando se contabilizan únicamente marineros o "gente de mar" podemos discernir el número de los dedicados a una u otra actividad marítima. Dependiendo pues de los datos aportados por las fuentes consultadas, nos veremos obligados a utilizar distintamente los términos señalados. Por "matriculados" haremos referencia a marineros y maestrantes en su conjunto; por "gente de mar", a marineros de barcos mercantes y pesqueros.

Aún resulta imprescindible una última observación sobre la Matrícula de Mar. Al ser una institución obligatoria e indudablemente onerosa para navegantes y oficios de construcción naval, la población afectada trataba de eludir su cumplimiento (15). Las ocultaciones deben ser tenidas en cuenta, pues, presumiéndose que el número de los efectivos humanos dedicados a actividades económicas marítimas debía ser superior al reflejado en las diversas revistas o recuentos oficiales llevados a cabo.

La "gente de mar" matriculada en El Puerto a finales del siglo XVIII alcanzaba la cifra de 773 personas (16). En los mismos años los efectivos de Sanlúcar eran de 346 personas (17). En tanto que Muñoz

(13) Ibídem, pp. 190 y 197.

(14) Se incluyen entre tales oficios de maestranza la calafatería, tonelería, velería, etc.

(15) FERNANDEZ, Jorge y MARTINEZ SHAW, Carlos: op. cit., p. 186. Sobre las negativas repercusiones del sistema de Matrícula en la actividad pesquera, puede consultarse a MALDONADO ROSSO, Javier: "Matrícula de Mar versus desarrollo pesquero. El Puerto de Santa María, 1858". Revista de Historia de El Puerto, 4, 1990, pp. 91-101.

(16) Archivo-Museo D. Alvaro de Bazán, Matrículas, G.I., leg. 1883.

(17) Ibídem. 
Pérez recoge la cifra de 437 pescadores para Sanlúcar en 1803 (18). Diferencia que en 1846, según los datos aportados por Igartuburu, se había trocado ligeramente a favor de Sanlúcar, con 712 matriculados, frente a 638 de El Puerto (19). En ese medio siglo que separa ambas fechas, la actividad mercantil de El Puerto había decrecido. La quiebra del comercio marítimo gaditano con las colonias americanas (20) debió afectar a El Puerto de Santa María, agravando la que ya era una prolongada crisis al respecto de la otrora floreciente ciudad mercantil (21). También el descenso del abastecimiento de productos hortofrutícolas a Cádiz durante las primeras décadas del siglo, hubo de ser acusado por el comercio local de cabotaje (22).

Centrándonos, como vamos a hacerlo én breve, en la pesca del bou a finales de la década de los sesenta del siglo XIX, hemos contabilizado los efectivos humanos dedicados a la pesca en El Puerto en 1869. Hemos utilizado para ello el padrón vecinal de tal año (23). El apartado de profesión, como ocurre en la mayoría de estos documentos, contiene ambigüedades. Casi todos los asientos relativos a este subsector aparecen con la lacónica denominación "mar", bajo la que encontramos a conocidos armadores, y en la que deben incluirse otras profesiones relacionadas con la actividad pesquera: rederos, hiladores, etc. Con menor frecuencia aparecen las denominaciones "matriculado", "armador", "marinero", e incluso otras como la de "bolichero", que hace referencia expresa a un tipo de pescador. La cantidad total que obtenemos es de 780 personas dedicadas a esta actividad. Proporcionalmente, ese número de "gente de mar" representaba el 11 por ciento, aproximadamente, de la población activa portuense en 1869 (24).

La cifra absoluta es similar a la citada para principios y mitad de siglo. No obstante, también en esas dos décadas de los años cincuenta y sesenta la composición de tales efectivos debió seguir experimentando considerables cambios, continuación de los ya apuntados líneas atrás. A esas alturas del siglo, otras varias causas se habían unido ya a

(18) MUÑOZ PEREZ, José: La pesca en la desembocadura del Guadalquivir. Cádiz, 1972.

(19) IGARTUBURU, Luis de: Manual de la provincia de Câdiz, 1847.

(20) GARCIA-BAQUERO, Antonio: Andalucia en la carrera de Indias (1492-1824). Sevilla, 1986, pp. 192 y ss.

(21) IGLESIAS, Juan José: op. cit.

(22) MALDONADO ROSSO, Javier: op. cit. p. 29

(23) A.M.E.P.S.M., Padrón Vecinal 1869. Agradecemos la colaboración que en el vaciado de tal padrón nos prestó María Dolores González.

(24) Ibídem. 
las señaladas anteriormente. El establecimiento de una conducción subterránea metálica para llevar las aguas de los manantiales de La Piedad -en el término de El Puerto de Santa María- hacia Cádiz (25), traería la finalización de su transporte en barcas (26), y la consiguiente disminución del tráfico de cabotaje en la Bahía. La puesta en funcionamiento de tramo de ferrocarril Puerto Real-Cádiz, que venía a unir la capital provincial con El Puerto, parece que incidió en igual sentido en lo que al tráfico de cabotaje se refiere.

\section{LA PESCA DEL BOU EN LOS AÑOS 60}

Tal como adelantábamos líneas atrás, en el siglo XVIII comenzó a operarse la transición del ciclo antiguo al moderno en la pesca española (27). A las tradicionales pesqueras de suspensión -con anzuelos y redes- y de arrastre "cabo en tierra" (28), vino a sumarse la pesca de arrastre "a flote" (29) y a gran escala. Con ella se introducían trascendentales innovaciones técnicas y modificaciones notorias en las relaciones de producción del sistema pesquero anterior.

De entre las artes de arrastre, la pesca del bou -llamada así por su semejanza con la yunta de bueyes, al practicarse por una pareja de barcos que tiraban al unísono de un gran arte que barría los fondos marinos como si de un arado se tratase- fue sin duda la más importante y cuestionada. El origen de esta modalidad de pesca parece encontrarse en Francia, desde cuya costa mediterránea se extendería a los litorales catalán y levantino. Los datos más antiguos que se tienen al respecto en aguas españolas corresponden a Cataluña y están en torno a fines e inicios del primer y segundo cuartos del siglo XVIII

(25) Ibídem, sección Aguas.

(26) LOPEZ MENA, Inmaculada: "Notas sobre la obra de conducción de agua a la ciudad de El Puerto de Santa María (1721-1741)", Revista de Historia de El Puerto, 2 , 1989, pp. 77-90; y GONZALEZ BELTRAN, Jesús Manuel: Abastecimiento de agua en El Puerto de Santa Maria del siglo XVIII. "La obra de la Fuente,, El Puerto de Santa Maria, 1989 , pp. 49 y 52.

(27) URTEAGA, Luis: La tierra esquilmada, Barcelona, 1987, pp. 38 y ss.; y COMPAN VAZQUEZ, Diego: "La pesca marítima en Andalucia", en Geografia de Andalucía, 1989, T.V., pp. 201-279.

(28) Son modalidades de arrastre "cabo en tierra" aquellas en las que un grupo de pescadores, desde playas arenosas, tira a mano de los cabos de un arte llevado agua adentro por una embarcación. La más importante y practicada era la modalidad conocida como "jábega".

(29) Empleamos la locución "pesca de arrastre a flote" para diferenciarla de la de "cabo en tierra". La pesca de arrastre a flote era la practicada en y desde embarcaciones. 
(30). Según Compán Vázquez, tras 1740, armadores catalanes y valencianos, avezados ya en esta pesquera, la introdujeron en las costas atlánticas peninsulares, convirtiéndose las localidades de la Bahía de Cádiz en los principales establecimientos de estas empresas pesqueras (31). Los conflictos de estos armadores con los pescadores de tales localidades, y entre sí mismos, constituyeron elementos característicos de la pesca de estas poblaciones durante parte del siglo XIX. Los pescadores de técnicas tradicionales se quejaban de la disminución de las capturas: consecuencia no sólo de la mayor capacidad del nuevo sistema sino de su poder esquilmador, así como de la destrucción de sus artes de pesca por parte de los de arrastre. Simultáneamente, entre los armadores catalanes y valencianos asentados en Cádiz y El Puerto de Santa María, respectivamente, se libró una dura competencia, con enfrentamientos físicos inclusive, por el control de los ricos caladeros de la zona (32).

En El Puerto de Santa María se practicaban en la segunda mitad del siglo XIX diversos sistemas de pesca, tanto "cabo en tierra" como "a flote", pero el más importante de ellos era la pesca del bou. Esto era así, no sólo por la dimensión de la flota de esta modalidad, sino por el tonelaje desplazado por la misma, por su volumen de capturas y por la tripulación empleada. Poseemos datos para fines de los años sesenta que nos permiten un análisis más pormenorizado de este sistema de pesca (33). En 1868 concretamente, fecha a la que se refieren los datos en cuestión, eran 20 las parejas de bous matriculadas en esta ciudad, esto es, 56 embarcaciones. Tales suponían el 8,25 por ciento de la flota de parejas de bous del Estado. Sanlúcar de Barrameda, la otra gran base pesquera del litoral atlántico bajo-andaluz, tenía 24 parejas. Cádiz, por su parte, contaba con 8.

Las embarcaciones eran de los tipos faluchos y barcas, con aparejo de vela latina; de distintas dimensiones y tonelajes. Lo más usual es que tuviesen una treintena de pies de eslora y un porte de 10 toneladas, pero también las había más pequeñas que se dedicaban a la pesca del bou. Los faluchos que se empleaban para cazonales eran más cortos de eslora y desplazaban unas pocas toneladas menos. Más pequeñas aún eran las barquillas que se utilizaban para el arte dẹ cor-

(30) SAÑEZ REGUART, Antonio: op. cit., vol. I, p. 322.

(31) COMPAN VAZQUEZ, Diego: op. cit., p. 224.

(32) A.M.A.B., A.P., leg. 2.025.

(33) Anuario de la Comisión Permanente de Pesca, 1868; Madrid, 1869; y relación de embarcaciones pesqueras del bou (A.M.A.B., Pesca, A.P., leg. 2.137). 
del. El valor de las 28 parejas del bou portuense representaba el 17 por ciento del total apreciado para la flota del bou que operaba en el país (34). Este dato, sin embargo, debemos tomarlo con precaución por cuanto en cartas de pago de la época los precios que encontramos para las parejas de embarcaciones del bou son notablemente inferiores a los que ofrecen las fuentes oficiales (35). Bien se nos escapan pertrechos a considerar o estamos ante un intento de los armadores de sobredimensionar el capital fijo invertido en sus empresas. Probablemente con la finalidad de oponer argumentos económicos a la pretensión de ciertos sectores conservacionistas de que se prohibiera, por antiecológica, la pesca del bou (36).

En cuanto a la mano de obra empleada en este tipo de pesca, el número preciso de marineros, en la zona en cuestión, era de 16 por pareja, incluyendo a los patrones de ambas embarcaciones; lo que haría un total teórico de 448 tripulantes. Esta cantidad suponía el 10 por ciento de los marineros del bou del Estado y el 65-70 por ciento de la "gente de mar" censada en El Puerto a fines de esos años sesenta (37).

El volumen de las capturas obtenidas por las parejas matriculadas en El Puerto se situaba en una media anual de 84.000 arrobas de pescado: el 14 por ciento casi del total nacional (38). El valor medio de esas capturas suponía una cantidad media, igualmente anual, de 252.000 escudos; cifra que venía a representar, asimismo, el 14 por ciento del valor total de las capturas españolas (39). Como puede apreciarse se daba, al menos en 1868 , un equilibrio perfecto entre ambos porcentajes de volumen y precio de las capturas portuenses en el mercado nacional de la pesca del bou (Apéndice 2).

La propiedad de la flota del bou portuense presentaba en 1868 una estructura medianamente concentrada. Las 28 parejas existentes

(34) Ibídem.

(35) Archivo particular de D. Luis Suárez Avila (El Puerto de Santa María), compraventa de dos embarcaciones de la pesca del bou, entre José María Valle y Ramón Tey Soler, 1870.

(36) La pugna por la prohibición de la pesca del bou comenzó en el mismo siglo XVIII, y tuvo por principal adalid el ya mencionado Inspector de Marina, Antonio Sáñez Reguart. Durante todo el siglo XIX prosiguió la polémica al respecto, desempeñando en ella un destacado papel conservacionista la Comisión Permanente de Pesca. En lo referente al siglo XVIII, puede consultarse la ya citada obra de Luis Urteaga: "La tierra esquilmada".

(37) A.M.E.P.S.M., Padrón Vecinal, 1869.

(38) Anuario de la Comisión Permanente de Pesca, 1868; Madrid, 1869.

(39) Ibídem. 
dicho año pertenecían a 20 armadores, un 25 por ciento de los cuales reunía la mitad de las mismas. Sobresalía en importancia la empresa José Montero Hermanos, propietaria de 4 parejas; también la de José María Valle, con 3; siguiéndole con dos parejas José María Ponce, Vicente Catalín y María Consolación Pérez. En Cádiz la propiedad estaba más concentrada, perteneciendo la mitad de la flota del bou al negociante Manuel García Quintana (40).

De los armadores portuenses de parejas de bous, una tercera parte al menos eran ellos mismos los patrones de sus propias embarcaciones. En tales casos, se trataba de propietarios de una sola pareja de embarcaciones. Del resto, un tercio aparece como "armadores", y el otro como "comerciantes". Pero por lo que hemos obtenido de los cuadernos de contribuyentes de los años 1868-69, estos armadores no se dedicaban, en general, a otros negocios que al de la pesca y demás con ella directamente relacionados (Apéndice 3). Así, el ya citado José María Valle era en esos años arrendatario de la pescadería de El Puerto, en la cantidad de 1.739 escudos (41). La totalidad casi de los armadores de bous de El Puerto vivían en el barrio marinero de la localidad, que se extendía a lo largo de la orilla derecha del tío Guadalete. $Y$ lo hacían, también ellos, en casas de vecinos y no en viviendas unifamiliares (42).

También es de destacar la escasa participación de este grupo de propietarios en la vida política y en las instituciones públicas locales. Donde sí se mostraban particularmente activos los armadores de la pesca del bou portuense era en sus conflictivas relaciones con la Administración pesquera. En estas aguas y no en las de la política local era donde se dirimían sus intereses. Este sistema de pesca, como ya señalamos líneas atrás, ocasionó airadas controversias entre partidarios y detractores de la misma. Decretada su supresión, una vez más, en esos años sesenta del pasado siglo, el peso opositor de tal medida correspondió a los armadores del bou en El Puerto de Santa María y de Sanlúcar de Barrameda. En este pulso por el mantenimiento de la pesca del bou, los respectivos ayuntamientos apoyaron a los armadores ante la Corona (43). La persistencia de sus reclamaciones logró modificar en 1867 el Reglamento de la Pesca del Bou, promulgado dos

(40) Archivo Museo D. Alvaro de Bazán; Pesca, a.P., leg. 2.137.

(41) A.M.E.P.S.M.; Matrícula del subsidio Industrial y de Comercio 1868-69, copia de 1870 .

(42) Ibídem, Padrón Vecinal 1869.

(43) A.M.E.P.S.M., A.C., 1858, f. 413. 
años antes tan sólo. No obstante, se incumplió sistemáticamente, y no sólo por parte de los armadores, sino de la propia Administración, que año tras año concedía autorizaciones "excepcionales" para que la mitad de las parejas de bous de los puertos que lo solicitaban pescasen durante la época de veda (44).

\section{CONSIDERACIONES FINALES}

Los dos principales factores con los que hemos operado en nuestro análisis -dimensión de la flota pesquera y volumen de la población activa local empleada en la pesca- arrojan un balance positivo sobre la evolución de este subsector económico en El Puerto de Santa María durante el siglo XIX.

El considerable aumento del número de embarcaciones pesqueras a lo largo de la centuria fue espectacular. No puede calificarse de otra manera un incremento del 360 por ciento (Apéndice 4). Pero más importancia que a las cifras debe concedérsele a la tipología de las embarcaciones y a los sistemas de pesca para los que eran empleadas. En este sentido destaca la flota de parejas del bou. Este arte de pesca, como hemos tenido ocasión de señalar líneas atrás, empleaba la mayoría de los efectivos humanos del subsector, aportaba el volumen más considerable de capturas y desplazaba los mayores tonelajes. En contraste con los negativos efectos ecológicos que ocasionaba, esta modalidad hacía de El Puerto decimonónico una de las bases pesqueras más importantes del litoral suratlántico andaluz (Apéndice 5), al tiempo que lo situaba, igualmente, en un destacado nivel estatal de este tipo de pesca.

Los problemas metodológicos planteados nos impiden conocer con exactitud los efectivos humanos dedicados a la actividad pesquera en El Puerto. Sostenemos, no obstante, la hipótesis de que el mantenimiento del número absoluto de personas empleadas en actividades económicas marítimas a lo largo de los tres cuartos de siglo para los que contamos con datos, esconde notables cambios en su composición. Por las razones ya apuntadas, el número de pescadores debió crecer con el correr del siglo, al tiempo que el de tripulantes de mercantes debió disminuir. Se trata, insistimos, de una hipótesis sobre la que habremos de continuar trabajando. Ello al margen de la evolución global de la población

(44) Anuario de la Comisión Permanente de Pesca, 1868; Madrid, 1869. 
activa del subsector, que a fines de siglo acusó un descenso (45), en el contexto de la crisis finisecular sufrida por la ciudad.

La evolución de la flota y de la tripulación pesqueras en esta localidad evidencian que durante el período objeto de nuestro estudio, se aprovecharon las magníficas ventajas naturales de la zona y las oportunidades que se presentaron al desarrollo pesquero: los caladeros de la plataforma continental, muy apropiados para la pesca de arrastre, fueron explotados intensivamente (46); y la ampliación del mercado interior, gracias al desarrollo de otros sectores económicos y de los medios de transporte, particularmente el ferrocarril.

Aunque no estemos aún en condiciones de determinar la contribución de la pesca al producto interior bruto de la economía portuense del pasado siglo, es indudable que este subsector tuvo una importancia considerable en la misma, como creemos haber apuntado. Debiendo ser consideradas además las actividades indirectas que generaba.

APENDICE 1 (a)

FLOTA PESQUERA PORTUENSE EN 1887

\begin{tabular}{ccc}
$\begin{array}{c}\text { Embarcaciones con } \\
\text { artes de arrastre }\end{array}$ & $\begin{array}{c}\text { Emb. con artes } \\
\text { de suspensión }\end{array}$ & $\begin{array}{c}\text { Total } \\
\text { embarcaciones }\end{array}$ \\
\hline
\end{tabular}

Parejas de bou Lavadas

32

3

171

238

\section{APENDICE 1 (b)}
DETALLE DE LOS ARTES DE PESCA EMPLEADOS POR LA FLOTA PESQUERA PORTUENSE EN 1887

Embarcaciones con artes de arrastre

Embarcaciones con artes de suspensión

\begin{tabular}{lrlc}
\hline Tipo & N.. & Tipo & N. \\
\hline Parejas de bous & 32 & Bonitera & 40 \\
Lavada & 3 & Ballestilla & 30
\end{tabular}

(45) MARCHENA DOMINGUEZ, José: "Estructuración socioprofesional y electoral de El Puerto de Santa María en 1890", Revista de Historia de El Puerto, 6, 1991; pp. 53-78.

(46) MUÑOZ PEREZ, José: op. cit., pp. 39-56. 
Embarcaciones con artes de arrastre
Embarcaciones con artes de suspensión

\begin{tabular}{lll}
\hline Tipo & No. & N.o \\
\hline & Cordel & 24 \\
& Cazonal & 14 \\
Nasa & 10 \\
& Curricán & 10 \\
Tarralla & 10 \\
& Espinel & 8 \\
& Cuévano & 6 \\
& Palillos & 6 \\
& Palangre & 5 \\
Trasmallo & 3 \\
& Corredera & 2 \\
& Cerco & 2 \\
& Candil & 1
\end{tabular}

Fuente: VERA Y CHILIER, Francisco Asís de: "Memoria de la pesca en Cádiz y su provincia". Madrid, 1985, pp. 27 y 38-39. Clasificación corregida.

APENDICE 2

INDICADORES DE LA PESCA DEL BOU EN EL PUERTO DE SANTA MARIA EN RELACION CON EL TOTAL NACIONAL (1868)

El Puerto

\% del total español

N. parejas

28

8,25 flota

Valor parejas

$154.000 \mathrm{esc}$.

$17,00 \%$

$84.000 \mathrm{a}$.

$14,00 \%$

Valor capturas anuales

252.000 esc.

$14,00 \%$

Tripulantes

$448\left(^{*}\right)$

$10,00 \%$

Fuente: Anuario de la Comisión Permanente de Pesca, 1868; Madrid, 1869. Elaboración propia. Valor en escudos. Capturas en arrobas.

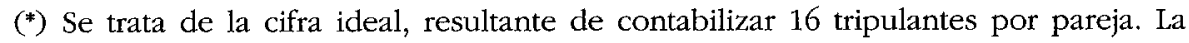
cifra real, no obstante, no parece que difiera en exceso de la citada. 


\section{APENDICE 3 \\ RELACION DE ARMADORES DE LAS PAREJAS DE BOUS DE EL PUERTO DE SANTA MARIA, 1868}

\begin{tabular}{|c|c|c|}
\hline Nombre & Profesión (*) & N.o de parejas \\
\hline Juan de Dios Sevilla & En la mar & 1 \\
\hline José María Ponce & Armador & 2 \\
\hline José María Valle & $"$ & 3 \\
\hline José Montero y hermanos & Comerciante & 4 \\
\hline Ramón Chulión & Comercio & 1 \\
\hline José Herrero & Armador & 1 \\
\hline Francisco Sevilla & En la mar & 1 \\
\hline Juan Rico & Armador & 1 \\
\hline María Consolación Pérez & $"$ & 2 \\
\hline José Vicente Pérez & En la mar & 1 \\
\hline Vicente Catalín & Comerciante & 2 \\
\hline José Montero y Ortega & Armador & 1 \\
\hline Domingo Laherrán & Comerciante & 1 \\
\hline Maria Angeles Lage & Comerciante & 1 \\
\hline Antonio Sevilla & En la mar & 1 \\
\hline Tadeo Tey & Comerciante & 1 \\
\hline Antonio Cortés & En la mar & 1 \\
\hline José María Cortés & $"$ & 1 \\
\hline Antonio José Maique & $"$ & 1 \\
\hline Andrés Aguado & Del comercio & 1 \\
\hline \multirow[t]{2}{*}{20 propietarios } & $\begin{array}{l}7 \text { en la mar } \\
6 \text { armadores }\end{array}$ & \\
\hline & 7 comerciantes & 28 \\
\hline
\end{tabular}

Fuente: Archivo Museo D. Alvaro de Bazán, Pesca. A.P., leg. 2.137. Elaboración propia.

${ }^{*}$ ) Se mantienen las denominaciones que aparecen en la fuente documental. 


\section{APENDICE 4 \\ EVOLUCION DIMENSIONAL DE LA FLOTA PESQUERA PORTUENSE (1765-1887)}

\begin{tabular}{lccc} 
Años & $\mathbf{1 7 6 5}$ & $\mathbf{1 7 9 9}$ & $\mathbf{1 8 8} 7$ \\
\hline N.. de embarcaciones & 23 & 49 & 238
\end{tabular}

Fuentes: FERNANDEZ, Jorge y MARTINEZ SHAW, Carlos: "La pesca en la España del siglo XVIII. Una aportación cuantitativa (1758-1765)", Revista de Historia Económica, 3 (1984); VERA Y CHILIER, Francisco Asís de: "Memoria sobre la pesca en Cádiz y su provincia". Madrid, 1985, pp. 27 y 38-39; y Archivo Museo D. Alvaro de Bazán, Matrículas, G.I., leg. 1883.

\section{APENDICE 5 \\ EMBARCACIONES DEDICADAS A LA PESCA DEL BOU EN LA BAHIA DE CADIZ (1865-1887)}

1865

1878

1887

\begin{tabular}{lcccccc}
\hline Localidades & N.o de & N.o de & N.o de & N.. de & N.o de & N.. de \\
& parejas & embarc. & parejas & embarc. & parejas & embarc.
\end{tabular}

Cádiz

8

16

4

8

El Puerto de

Santa María

28

56

33

66

32

64

Sanlúcar de

Barrameda

24

48

26

$53\left({ }^{*}\right)$

28

56

Fuente: VERA Y CHILIER, Francisco Asís de: "Memoria sobre la pesca en Cádiz y su provincia". Madrid, 1895, pp. 26-27. Datos corregidos.

(*) Puede que se contabilice aquí alguna embarcación "enviada". 


\section{APENDICE 6 \\ EVOLUCION DE LA POBLACION ACTIVA DEDICADA A \\ ACTIVIDADES MARITIMAS. \\ EL PUERTO DE SANTA MARIA (1799-1869) (*)}

N. de trabajadores maritimos

\begin{tabular}{lllll}
\hline Años & $\begin{array}{l}\text { Gente de mar } \\
\text { pescadores y } \\
\text { marineria merc. }\end{array}$ & Maestranza & Total & $\begin{array}{c}\text { N.o de } \\
\text { matricul. }\end{array}$ \\
\hline 1799 & 497 & 129 & $626(* *)$ & - \\
1816 & 502 & - & 502 & - \\
1846 & - & - & - & 638 \\
1869 & - & - & 785 & - \\
1890 & 636 & - & 636 & -
\end{tabular}

Fuente: A.M.A.B., Matrícula General., I, leg. 1.883. A.M.E.P.S.M. Padrones vecinales 1816 y 1869.

IGARTUBURU, Luis: "Manual de la provincia de Cádiz". Cádiz, 1847. Y MARCHENA DOMINGUEZ, José: "Estructuración socioprofesional y electoral de El Puerto de Santa María en 1890". Revista de Historia de El Puetto, 6 (1991), pp. 53-78.

Elaboración propia.

(*) Dada la falta de homogeneización de los datos aportados por las fuentes consultadas, el cuadro recoge en dos bloques la población activa dedicada a actividades marítimas, pero en ningún caso las cifras de uno y otro (trabajadores marítimos y matriculados) son acumulativas.

(**) El n.. era sin duda mayor, pues no se contabilizaban desertores y jubilados, que en algunos casos seguían ejerciendo trabajos de mar. 